\title{
Altered movement patterns and muscular activity during single and double leg squats in individuals with anterior cruciate ligament injury
}

\author{
Anna Trulsson ${ }^{1,2^{*}}$, Michael Miller ${ }^{1}$, Gert-Åke Hansson ${ }^{3}$, Christina Gummesson ${ }^{4 \dagger}$ and Martin Garwicz ${ }^{5 \dagger}$
}

\begin{abstract}
Background: Individuals with Anterior Cruciate Ligament (ACL) injury often show altered movement patterns, suggested to be partly due to impaired sensorimotor control. Here, we therefore aimed to assess muscular activity during movements often used in ACL-rehabilitation and to characterize associations between deviations in muscular activity and specific altered movement patterns, using and further exploring the previously developed Test for substitution Patterns (TSP).

Methods: Sixteen participants (10 women) with unilateral ACL rupture performed Single and Double Leg Squats (SLS; DLS). Altered movement patterns were scored according to TSP, and Surface Electromyography (SEMG) was recorded bilaterally in six hip, thigh and shank muscles. To quantify deviations in muscular activity, SEMG ratios were calculated between homonymous muscles on injured and non-injured sides, and between antagonistic muscles on the same side. Correlations between deviations of injured/non-injured side SEMG ratios and specific altered movement patterns were calculated.
\end{abstract}

Results: Injured/non-injured ratios were low at transition from knee flexion to extension in quadriceps in SLS, and in quadriceps and hamstrings in DLS. On injured side, the quadriceps/hamstrings ratio prior to the beginning of DLS and end of DLS and SLS, and tibialis/gastrocnemius ratio at end of DLS were lower than on non-injured side. Correlations were found between specific altered movement patterns and deviating muscular activity at transition from knee flexion to extension in SLS, indicating that the more deviating the muscular activity on injured side, the more pronounced the altered movement pattern. "Knee medial to supporting foot" correlated to lower injured/ non-injured ratios in gluteus medius $\left(r_{s}=-0.73, p=0.001\right)$, "lateral displacement of hip-pelvis-region" to lower injured/non-injured ratios in quadriceps $\left(r_{s}=-0.54, p=0.03\right)$ and "displacement of trunk" to higher injured/ non-injured ratios in gluteus medius $\left(r_{s}=0.62, p=0.01\right)$.

Conclusions: Deviations in muscular activity between injured and non-injured sides and between antagonistic muscular activity within injured as compared to non-injured sides indicated specific alterations in sensorimotor control of the lower limb in individuals with $\mathrm{ACL}$ rupture. Also, correlations between deviating muscular activity and specific altered movement patterns were suggested as indications of altered sensorimotor control. We therefore advocate that quantitative assessments of altered movement patterns should be considered in ACL-rehabilitation.

Keywords: Anterior cruciate ligament, Movement pattern, Muscular activity, Motor skills, Motor control, Single leg squat, Electromyography (EMG), Postural orientation, Assessment, Physiotherapy

\footnotetext{
* Correspondence: anna.trulsson@med.lu.se

${ }^{\dagger}$ Equal contributors

'Department of Health Sciences, Physiotherapy, Lund University, Lund,

Sweden

${ }^{2}$ Department of Rehabilitation Medicine, Skane University Hospital, Lund,

Sweden

Full list of author information is available at the end of the article
}

\section{Biomed Central}

(c) 2015 Trulsson et al.; licensee BioMed Central. This is an Open Access article distributed under the terms of the Creative Commons Attribution License (http://creativecommons.org/licenses/by/4.0), which permits unrestricted use, distribution, and reproduction in any medium, provided the original work is properly credited. The Creative Commons Public Domain Dedication waiver (http://creativecommons.org/publicdomain/zero/1.0/) applies to the data made available in this article, unless otherwise stated. 


\section{Background}

Altered movement patterns in individuals with Anterior Cruciate Ligament (ACL) injury have been demonstrated during gait, functional movements and common rehabilitative exercises [1-3]. In clinical practice of ACL injury evaluation and rehabilitation, assessments primarily focus on knee stability, muscular strength and/or knee symptoms [4-6], and since it has been argued that interventions should be based on functional performance tests [7], assessments of jump performance are also often used [8]. Still, none of these tests strongly predict the demonstrated alterations in movement patterns $[9,10]$.

The underlying mechanisms to altered movement patterns in individuals with ACL injury, are to date not fully understood, but impaired sensorimotor control - including delayed muscular responses, altered timing, co-activation or proprioception - likely plays an important causal role $[2,11]$. Indeed, altered afferent sensory input due to joint injury and altered information processing in the central nervous system can lead to altered efferent output to muscles $[12,13]$. In addition, individuals with ACL injury demonstrate biomechanical instability due to increased knee-joint laxity between tibia and femur, with increased anterior-posterior translations and/or internal-external rotation, which may increase the risk of "giving-way" episodes (abnormal, sudden, painful displacement of tibia relative to femur during weight bearing) [14].

To provide a better understanding of the interplay between alterations in sensorimotor control and biomechanical joint stability following knee injury, and to further explore the previously developed Test for Substitution Patterns (TSP) for the assessment of alterations in functional movements and common rehabilitative exercises, we investigated movement patterns and muscle activity in individuals with ACL rupture. Since anticipatory postural muscular activity can be altered in individuals with ACL injury $[13,15]$, the notion was that specific altered movement patterns are associated with deviations in muscular activity between injured and non-injured sides. If there is such association, it could have implications for future rehabilitation guidance where detection and improvement of altered movement patterns associated with deviations in muscular activation should be considered in ACL rehabilitation.

To assess altered movement patterns, reliable, valid and preferably quantitative observational assessments of movement patterns are needed. In this study we focused on the movements Single Leg Squat (SLS) and Double Leg Squat (DLS), since these movements have previously been used in standardized assessments in individuals with knee-complaints, have proved to be both valid and reliable and are often used as functional rehabilitative exercises [16-19]. During SLS and DLS, altered movement patterns have been observed as poor alignment manifested as excessive medial displacement of the knee in relation to the foot or hip, an alignment that is reported to be especially disadvantageous in individuals with ACL injury since it can cause an increased risk for re-injuries during "giving-way" episodes [20]. Moreover, the SLS and DLS can be used in knee rehabilitation not only for evaluation, but also as a functional weight-bearing training task to improve neuromuscular control [21].

However, assessments of SLS and DLS have in different studies been performed in somewhat different ways; either dichotomously or on an ordinal scale for segmental or overall movement quality $[16,18,19,22]$. Furthermore, poor alignment in the lower extremity is not dependent only on knee joint position, but also on postural orientation of other joints in the lower leg and/or trunk (the ability to stabilize body segments in relation to each other and to the environment [23]), maintained by the dynamic multi-joint stabilization [13]. It has therefore been suggested that the total kinetic chain, from foot to neck, should be considered during these movements, and various tests have been developed for this purpose $[3,9,18]$. In this study, we used the Test for Substitution Patterns, since the TSP contains the SLS and DLS and has been evaluated for assessment of altered movement patterns in the entire kinetic chain in individuals with ACL injury and in controls [3,9]. In previous studies of TSP, individuals with ACL injury showed more and/or more pronounced altered movement patterns around the injured knee-joint, adjacent joints and in the trunk as compared to noninjured controls, and the TSP assessment was found to have a good inter- and intra-rater reliability at group level $[3,9]$. The SLS and DLS, included in the TSP, are in this context scored for specific, predefined altered movement patterns associated with knee complaints and often used also as rehabilitative exercises [24].

To understand the muscle control strategies used by individuals with ACL injury performing SLS and DLS tasks more strenuous than gait, but still not as demanding as jump tests - we combined the assessments of altered movement patterns with assessments of muscle activity by the use of simultaneous surface electromyography (SEMG). Electromyography is often used in kinesiological studies and reflects motor unit action potentials. The technique has been used for characterization of for example dynamic joint stability and compensatory mechanisms following ACL injury $[25,26]$. SEMG also has been studied during SLS and DLS - although preferentially in non-injured individuals $[27,28]$.

The aims of the present study were i) to quantitatively characterize deviations in muscular activity in six muscles of the hip, thigh and shank during SLS and DLS performance in individuals with a mechanical instability due to a unilateral, total ACL rupture, and ii) to quantitatively characterize associations between 
specific altered movement patterns and specific deviations in muscular activity.

\section{Methods \\ Participants}

Sixteen participants (10 women), aged 19-48 years (mean 29.5, SD 9.5) with a total, unilateral, non-reconstructed ACL rupture sustained 2-11 months (mean 3.6, SD 2.3) before testing, volunteered to participate in this crosssectional, experimental study (Table 1). An orthopedic surgeon verified the diagnosis through clinical examination; all participants had a biomechanical kneeinstability with an increased sagittal laxity indicated by a positive Lachman test and a positive pivot shift test. The injury also was verified with magnetic resonance imaging (MRI) and/or arthroscopy at the Department of Orthopedics at Lund University Hospital, Sweden, where all participants who volunteered had consulted an orthopedic surgeon during the testing period from March 2012 to January 2013. Individuals with knee-pain, injury to the contralateral knee, concomitant symptomatic or repairable

\section{Table 1 Characteristics of the 16 participants with ACL} rupture

\begin{tabular}{|c|c|}
\hline Body Mass Index (BMl; kg/m²), mean (SD) & $24.6(5.1)$ \\
\hline Dominant side: right & 14 \\
\hline Injured side: dominant & 6 \\
\hline $\begin{array}{l}\text { Participants with Magnetic Resonance Imaging-verified } \\
\text { associated meniscal afflictions }\end{array}$ & 5 \\
\hline collateral ligament injury & 5 \\
\hline compressive trauma/bone bruise & 13 \\
\hline KOOS sport/recreation, mean (SD) & $38.1(32.3)$ \\
\hline KOOS quality of life, mean (SD) & $44.7(21.1)$ \\
\hline IKDC, mean (SD) & $58.2(16.3)$ \\
\hline Tegner activity scale before injury, median (min - max) & $6(3-10)$ \\
\hline $\begin{array}{l}\text { Tegner activity scale at the testing occasion, median } \\
\text { (min - max) }\end{array}$ & $3(1-6)$ \\
\hline TSP Total score non-injured side, median (min - max) & $0(0-5)$ \\
\hline TSP Total score injured side, median (min - max) & $9.5(2-20)$ \\
\hline p-value & $p \leq 0.000$ \\
\hline median difference, $95 \% \mathrm{Cl}$ & $6.5(5-12)$ \\
\hline \multicolumn{2}{|c|}{$\begin{array}{l}\text { KOOS = Knee Injury and Osteoarthritis Outcome Score. The } 2 \text { subscales sport/ } \\
\text { recreation and quality of life (range from } 0 \text { "extreme problems" to } 100 \text { "no } \\
\text { problems") were used in this study. } \\
\text { IKDC = the International Knee Documentation Committee Subjective Knee } \\
\text { Evaluation Form (ranging from } 0 \text { "absence of symptoms" to } 100 \text { "no limitations } \\
\text { of daily living"). } \\
\text { Tegner activity scale (ranging from } 1 \text { "low activity like walking on even } \\
\text { ground" to } 10 \text { "high activity like American football"). } \\
\text { TSP = Test for Substitution Patterns (comprising } 5 \text { test-movements; total score } \\
\text { ranging from } 0 \text { "no substitution pattern" to } 54 \text { "very clearly present, subject } \\
\text { performed very poorly" where altered movements (substitution patterns) were } \\
\text { scored as observable, predefined deviations of postural orientation). } \\
\mathrm{SD}=\mathrm{Standard} \text { Deviation. } \\
95 \% \mathrm{Cl}=95 \% \text { Confidence Interval. }\end{array}$} \\
\hline
\end{tabular}

meniscal injury, major cartilage injury, fracture, patellofemural injury or instability, injury to/pain in back/other joint, injury to the nervous system or a known neurological disease or pregnancy were excluded. All participants but one had regular supervised physical therapy. All participants gave their written, informed consent, and the study was approved by the Regional Ethical Review Board in Lund, Sweden, Dnr 2010/387.

\section{Settings and procedure}

The participants were informed which test-movements to perform, but not what was observed in the TSP. All were allowed to try the test-movements before the electrodes and electrogoniometers were applied. They were asked to perform the test-movements at a standardized pace given by a Metronome ( 50 beats per minute; Joyo JM-65, Joyo Technology CO., LTD, Shenzhen, China). The participants performed the test-movements barefooted and dressed in shorts and T-shirt. During the SLS, unilateral fingertip support was permitted. The examiner gave standardized verbal and visual instructions according to the manual, and scored participants' performances during three trials at the same time as the SEMG and electrogoniometer measurements were recorded. After performing the test-movements, participants rated their knee symptoms, knee-function and activity level. The test session lasted about 90 minutes.

\section{Test-movements and TSP-scoring}

The test-movements primarily used in the present analysis were SLS and DLS, since these movements can be assessed in a reliable manner [16-19], are commonly used in both clinical work and in research, resemble activities of everyday life and are also used as common functional rehabilitative exercises. However, the complete TSP consists of five test-movements - SLS, DLS, forward lunge, tip-toe standing knee flexion and body-weight-altering, which were all conducted to assess TSP Total score (Table 1). The participants performed all five test-movements in a standardized order, with three consecutive trials of each test-movement $[3,9]$.

The altered movements (substitution patterns) scored in the SLS and DLS were scored according to a strict protocol presented and evaluated by Trulsson et. al. [3,9], and were observable, predefined deviations of postural orientation between the foot, knee, hip, trunk, arms and/ or neck as compared to the non-injured side; "knee medial to supporting foot", "pronation of foot", "lateral displacement of hip-pelvis region", "displacement of trunk" in the SLS and "displacement of body weight to either side" in the DLS. Substitution patterns were scored for each side separately using a four point, ordinal scale (0-3); " 0 ": no substitution pattern; "1": substitution pattern possibly present; "2": substitution pattern clearly present; "3": 
subject performed very poorly (e.g. with no similarity to the task or unable to perform the predefined number of trials). Points 1-3 were given when a specific substitution pattern was observed in at least two of the three trials of the test-movement. Consequently, in the present study, the possible score for an individual participant was 0 to 12 points for SLS and 0 to 3 points for DLS. An experienced physical therapist specializing in knee injury rehabilitation and familiar with TSP assessments scored all participants' performances.

\section{Outcome measures}

The participants rated their knee symptoms as perceived during the past week and also retrospectively, as experienced just before the injury. The Swedish version of Knee Injury and Osteoarthritis Outcome Score, KOOS [4], a self-administered, validated questionnaire with 42 questions comprising five subscales, each ranging from 0 (extreme problems) to 100 (no problems) was used. The subscales sport/recreation and quality of life were used in this study (Table 1). The participants also rated their knee-function on the International Knee Documentation Committee Subjective Knee Evaluation Form (IKDC), consisting of 10 questions about symptoms and activity ranging from 0 to 100 , where 100 indicates absence of symptoms and no limitations in daily living [29]. Participants rated their activity level, according to Tegner activity scale graded from level 1 (low activity) to 10 (very high activity) [30]. Before injury, median activity level was 6 (activities such as badminton, tennis, alpine skiing, aerobics or cross country running). At the test occasion median activity level was 3 (bike riding, swimming or golf).

\section{SEMG}

To evaluate which muscles, electrode placements, procedure and pace to use when performing the test-movements, piloting with SEMG of 13 different muscles and protocol development was carried out in two individuals with ACL rupture (not included in the study) and four non-injured individuals. In the final protocol, SEMG was recorded bilaterally from gluteus medius, biceps femoris (long head), quadriceps femoris vastus lateralis, tibialis anterior, medial head of gastrocnemius and the peroneus longus muscle, using a 16 channel telemetric data logger (Mega Muscle tester ME6000, Mega Electronics Ltd, Kuopio, Finland; sampling rate $1024 \mathrm{~Hz}$ ). The Mega Win Software 3.1 was used to digitally filter the raw SEMG signals with a bandpass filter with cut off frequencies of 30 and $400 \mathrm{~Hz}$ and to calculate the root mean square value for epochs of 125 ms. Self-adhesive, silver/silver chloride surface electrodes (Ambu ${ }^{\circ}$ Neuroline 720, Ambu, Ballerup, Denmark) were placed in a bipolar configuration longitudinally on each muscle belly (inter-electrode distance $20 \mathrm{~mm}$ ) according to SENIAM recommendations [31]. The skin surface was prepared by shaving, if necessary, and with fine sandpaper and ethanol, and the same examiner mounted the electrodes for all participants. Before each test, SEMG signals were visually controlled during rest for background artifacts and poor electrode connection.

\section{Electrogoniometers}

For measurement of knee flexion/extension angle, strain gauge electrogoniometers (SG150, Biometrics Ltd., Newport, United Kingdom) with a measurement accuracy of $\pm 2^{\circ}$ were mounted on the lateral side of the right and left knees and signals were recorded on the same data logger as the SEMG signal. The electrogoniometers were attached with double sided medical tape, aligned so that the center of the electrogoniometer-sensor corresponded to the center of movement in the knee-joint and in a straight line from the participants' trochanter major of femur and lateral malleolus of fibula when standing with straight legs. The electrogoniometers were calibrated according to the manufacturer's instructions and were mounted by the same examiner for all participants.

\section{Video camera}

A camera (High-Definition Video 1080i; Canon HD, LEGRIA HV40, Canon Inc., Tokyo Japan), mounted on a tripod and capturing test-movements from the front, was synchronized $( \pm 40 \mathrm{~ms})$ with the SEMG measurements so that the TSP examiner also could assess testmovements after testing.

\section{Data analysis and statistics \\ Data analysis}

One examiner visually inspected the video according to a protocol defined in advance so that the trial with the most obvious altered movements was chosen for analysis. To analyze SEMG activity during the chosen trial, the Mega Win software was used to visualize SEMG amplitudes (microvolts, $\mu \mathrm{V}$ ) on a time-axis (milliseconds, $\mathrm{ms})$. The same examiner processed the SEMG recordings and identified the start and end of the trial by simultaneous inspection of the video and electrogoniometer recordings: the instance that the goniometer signal changed $+2^{\circ}$ during $0.1 \mathrm{~s}$ was defined as the start and the instance when the goniometer signal resumed starting-level was defined as the end of the test-movement. The mean durations of the SLS were $2.5 \mathrm{~s}$ (SD 0.5) and 2.4 s (SD 0.5) for the injured and non-injured sides, respectively and $2.6 \mathrm{~s}$ (SD 0.4) for the DLS.

For analysis, the SEMG-recording during testmovements was divided into 10 time epochs (bins). The time bins were evenly distributed over the duration of the test-movement, within the limits of the time resolution of the Mega Win software $(0.1 \mathrm{sec})$. A "pre-bin", bin 1, was added for the inclusion of anticipatory 
muscular activation just prior to the defined beginning of the test-movement, corresponding to $10 \%$ of the duration of the test-movement. Hence, 11 time bins, evenly distributed and starting slightly before the test-movement were used in the SEMG analysis.

The average amplitude for each of the 11 time bins was calculated by the Mega Win Software. However, comparisons and correlation calculations focused on preparatory muscular activity (time bin 1), the transition from flexion to extension (for individual participants either time bin 6 or 7) and the decline or cessation of muscular activity (time bin 11), given the crucial importance of these phases for the movement as a whole.

To obtain a measure of SEMG deviation - for each muscle, for each participant, for both SLS and DLS - that could be quantitatively compared to TSP scores, the ratio of average amplitude for each of the 11 time bins between injured and non-injured sides, $\mathrm{SEMG}_{\text {ratio }}$, was calculated in accordance with previous studies [32,33], so that equal activity of injured and non-injured sides would correspond to 1.0 [32]. To quantitatively characterize the activity in antagonistic muscles, a ratio of SEMG activity of quadriceps/hamstrings and tibialis anterior/gastrocnemius was calculated for bin 1, 6/7 and 11. Ratios were then compared between injured and non-injured sides.

\section{Statistics}

The Wilcoxon Signed Ranks Test was used to test for differences between the injured and non-injured sides with respect to TSP scores, $\mathrm{SEMG}_{\text {ratio }}$ and for the antagonistic activity ratio within the injured side in bins $1,6 / 7$ and 11 . Differences $\mathrm{p} \leq 0.05$ were considered statistically significant. Non-parametric confidence intervals (95\%) were calculated for the median of the paired differences [34]. For the correlation calculations between the $\mathrm{SEMG}_{\text {ratio }}$ and the results of the TSP, the Spearman's correlation coefficients $\left(r_{s}\right)$ were used, and correlations $r_{s}<-0.5$ or $r_{s} \geq 0.5$ are presented. All calculations and statistical analyses were carried out using SPSS version 11.5 and IBM SPSS Statistics version 20.0.

Data for the dominant/non-dominant leg were pooled in accordance with previous studies, in which subjects conducting movements similar to SLS and DLS were found to have a fairly symmetrical SEMG when comparing dominant and non-dominant sides [35].

\section{Results}

TSP-score

In accordance with previous studies, TSP scores were significantly higher on participants' injured side as compared to their non-injured side, for both SLS and DLS (Table 2). The two most frequent substitution patterns in SLS were "knee medial to the supporting foot" and "displacement of trunk" (both present in 9/16 participants). In
Table 2 Median TSP score for the Single Leg Squat (SLS) and Double Leg Squat (DLS)

\begin{tabular}{lcc}
\hline Test-movement & $\begin{array}{c}\text { Median (min - max) } \\
\text { TSP score on } \\
\text { injured side }\end{array}$ & $\begin{array}{c}\text { Median (min - max) } \\
\text { TSP score on } \\
\text { non-injured side }\end{array}$ \\
\hline SLS & $2(0-6)$ & $0(0-3)$ \\
Possible score: $0-12$ & median difference $1.0,95 \% \mathrm{Cl}(1.0-3.0)$ \\
DLS & $1(0-2)$ & $0(0-0)$ \\
Possible score: $0-3$ & median difference $1.0,95 \% \mathrm{Cl}(1.0-2.0)$ \\
& $\quad \mathrm{p}=0.001$ \\
\hline
\end{tabular}

Median (min - max) TSP score for the Single Leg Squat (SLS) and Double Leg Squat (DLS) respectively, as well as median difference with $95 \%$ confidence interval $(95 \% \mathrm{Cl})$ and $\mathrm{p}$-value for injured and non-injured sides, for the 16 participants with $\mathrm{ACL}$ rupture.

SLS and DLS are included in the Test for Substitution Patterns where altered movements (substitution patterns) were scored as observable, predefined deviations of postural orientation; for details see Subjects and Methods section.

DLS, 13/16 participants "displaced the body weight to non-injured side".

\section{SEMG}

In SLS, overall activity in time bins $1,6 / 7$ and 11 was similar in non-injured and injured sides, with three notable exceptions (Figure 1, Table 3). (For absolute amplitudes of SEMG during entire SLS and DLS performance, see Additional file 1). Prior to the beginning of movement, in bin 1, activity in peroneus longus was lower on the injured side, indicated by a $\mathrm{SEMG}_{\text {ratio }}$ of $0.55\left[\mathrm{Q}_{1}\right.$, $\mathrm{Q}_{3}$ 0.33, 0.88] ( $\left.\mathrm{p}=0.03\right)$. At transition from knee flexion to extension, activity in quadriceps vastus lateralis was lower on the injured side; $S E M G_{\text {ratio }} 0.69\left[\mathrm{Q}_{1}, \mathrm{Q}_{3} 0.62\right.$, 0.97] ( $p=0.05)$. At end of SLS, there was still a lower activity in quadriceps on the injured side; $\mathrm{SEMG}_{\text {ratio }} 0.73$ $\left[\mathrm{Q}_{1}, \mathrm{Q}_{3} 0.39,1.05\right](\mathrm{p}=0.05)$.

In DLS, activity prior to the beginning of the movement differed between injured and non-injured sides in four of the six muscles recorded (Figure 1, Table 3). The SEMG $G_{\text {ratio }}$ was $1.46\left[\mathrm{Q}_{1}, \mathrm{Q}_{3} 1.00,3.00\right]$, ( $\left.\mathrm{p}=0.04\right)$ for biceps femoris, $0.64\left[\mathrm{Q}_{1}, \mathrm{Q}_{3} 0.50,1.00\right](\mathrm{p}=0.04)$ for quadriceps, 0.61 $\left[\mathrm{Q}_{1}, \mathrm{Q}_{3} 0.17,0.92\right](\mathrm{p}=0.02)$ for tibialis anterior and 0.53 $\left[\mathrm{Q}_{1}, \mathrm{Q}_{3} 0.38,0.98\right](\mathrm{p}=0.02)$ for peroneus longus. At transition from knee flexion to extension, $\mathrm{SEMG}_{\text {ratio }}$ was $0.66\left[\mathrm{Q}_{1}, \mathrm{Q}_{3} 0.48,0.80\right](\mathrm{p}=0.02)$ for biceps femoris and $0.56\left[\mathrm{Q}_{1}, \mathrm{Q}_{3} 0.38,0.71\right](\mathrm{p}=0.003)$ for quadriceps. At the end of DLS there was lower activity on the injured side in three muscles - quadriceps vastus lateralis, SEMG $G_{\text {ratio }}$ $0.66\left[\mathrm{Q}_{1}, \mathrm{Q}_{3}\right.$ 0.44, 0.99] $(\mathrm{p}=0.01)$, tibialis anterior, 0.46 $\left[\mathrm{Q}_{1}, \mathrm{Q}_{3} 0.13,1.00\right](\mathrm{p}=0.02)$ and peroneus longus, 0.61 $\left[\mathrm{Q}_{1}, \mathrm{Q}_{3} 0.28,1.19\right](\mathrm{p}=0.04)$.

The activity in antagonistic muscles, calculated as a ratio of the SEMG activity of quadriceps/hamstrings within the 


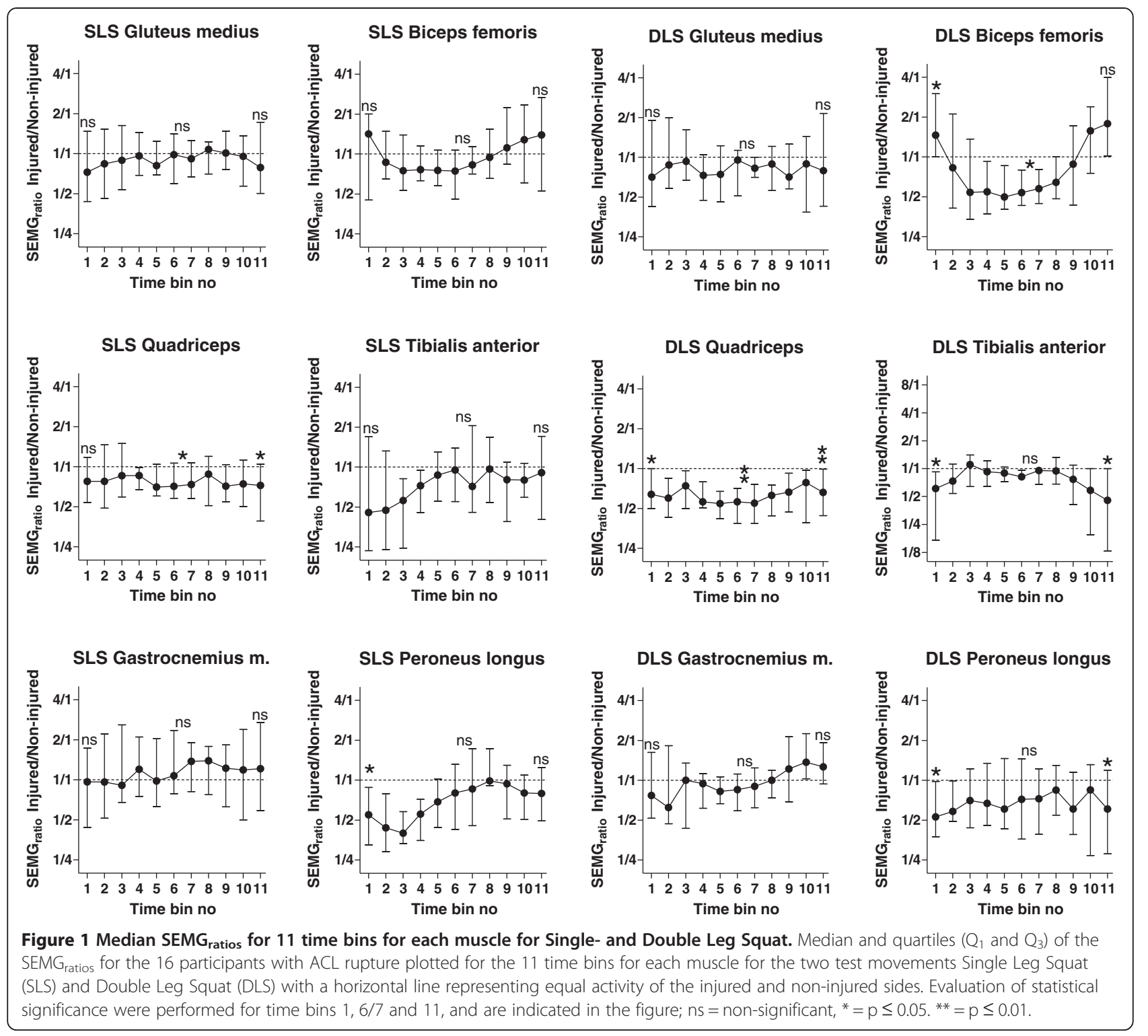

injured side was lower for the SLS on injured side in bin 11 , with a median of $1.80\left[\mathrm{Q}_{1}, \mathrm{Q}_{3} 1.07,2.67\right]$, as compared to the non-injured side, with a median ratio of $3.6\left[\mathrm{Q}_{1}, \mathrm{Q}_{3}\right.$ $2.02,5.73]$ and a median difference of $1.73,95 \% \mathrm{CI}-0.6$ to $4.5, \mathrm{p}=0.02$. For the DLS there was a lower quadriceps/ hamstrings ratio on injured side prior to the beginning of the movement in bin 1 , with a median of $1.9\left[\mathrm{Q}_{1}, \mathrm{Q}_{3} 0.73\right.$, 3.25], as compared to non-injured side of $4.5\left[\mathrm{Q}_{1}, \mathrm{Q}_{3} 2.92\right.$, 6.0] and a median difference of $2.5,95 \%$ CI 0.4 to $4.0, \mathrm{p}=$ 0.02 , and at end of DLS in bin 11, with a lower quadriceps/hamstrings ratio on injured side of $1.9\left[\mathrm{Q}_{1}, \mathrm{Q}_{3} 1.02\right.$, $3.68]$, as compared to on the non-injured side, with 4.3 $\left[\mathrm{Q}_{1}, \mathrm{Q}_{3} 3.52,7.64\right]$ and a median difference of $2.5,95 \% \mathrm{CI}$ 0.1 to $5.9, \mathrm{p}=0.03$. The only deviation in antagonistic activity on the injured side for the tibialis anterior/ gastrocnemius muscles was a lower activity at end of DLS in bin 11 , with a median on injured side of $0.3\left[\mathrm{Q}_{1}, \mathrm{Q}_{3}\right.$ $0.18,0.73]$, as compared to the non-injured side, with 1.14 $\left[\mathrm{Q}_{1}, \mathrm{Q}_{3} 0.54,5.07\right]$ and a median difference of $1.0,95 \% \mathrm{CI}$ 0 to $5.3, \mathrm{p}=0.004$.

\section{Correlations between TSP scores and SEMG ratio}

In SLS, "lateral displacement of the hip-pelvis region on the supporting side" was negatively correlated to $\mathrm{SEMG}_{\text {ratio }}$ of biceps femoris in time bin $1, \mathrm{r}_{\mathrm{s}}=-0.71$ ( $\mathrm{p}=0.002,95 \%$ $\mathrm{CI}-0.89$ to -0.33$)$, and to $\mathrm{SEMG}_{\text {ratio }}$ of quadriceps in time bin $6 / 7, r_{s}=-0.54(p=0.03,95 \% \mathrm{CI}-0.82$ to -0.06$)$. These findings indicate that the lower the muscle activity in biceps femoris on the injured side prior to the beginning of movement and the lower the activity on the injured side in 
Table 3 SEMG $_{\text {ratios }}$ for the Single Leg Squat (SLS) and the Double Leg Squat (DLS)

\begin{tabular}{|c|c|c|c|c|c|c|}
\hline \multicolumn{7}{|l|}{ SLS } \\
\hline \multirow[t]{2}{*}{ Muscle } & Time bin 1 & $p$ & Time bin 6/7 & $p$ & Time bin 11 & $\mathrm{p}$ \\
\hline & \multicolumn{2}{|l|}{ Median $\left(\mathrm{Q}_{1}, \mathrm{Q}_{3}\right)$} & \multicolumn{2}{|l|}{ Median $\left(\mathrm{Q}_{1}, \mathrm{Q}_{3}\right)$} & \multicolumn{2}{|l|}{ Median $\left(\mathrm{Q}_{1}, \mathrm{Q}_{3}\right)$} \\
\hline Quadriceps vastus lateralis & $0.78(0.54,1.18)$ & ns (0.12) & $0.69(0.62,0.97)$ & 0.05 & $0.73(0.39,1.05)$ & 0.05 \\
\hline Peroneus longus & $0.55(0.33,0.88)$ & 0.03 & $0.72(0.44,1.36)$ & ns (0.16) & $0.80(0.49,1.25)$ & ns (0.16) \\
\hline \multicolumn{7}{|l|}{ DLS } \\
\hline \multirow[t]{2}{*}{ Muscle } & Time bin 1 & $\mathrm{p}$ & Time bin 6/7 & $\mathrm{p}$ & Time bin 11 & $p$ \\
\hline & \multicolumn{2}{|l|}{ Median $\left(\mathrm{Q}_{1}, \mathrm{Q}_{3}\right)$} & \multicolumn{2}{|l|}{ Median $\left(\mathrm{Q}_{1}, \mathrm{Q}_{3}\right)$} & \multicolumn{2}{|l|}{ Median $\left(\mathrm{Q}_{1}, \mathrm{Q}_{3}\right)$} \\
\hline Biceps femoris & $1.46(1.00,3.00)$ & 0.04 & $0.66(0.48,0.80)$ & 0.02 & $1.78(1.02,3.96)$ & ns (0.11) \\
\hline Quadriceps vastus lateralis & $0.64(0.50,1.00)$ & 0.04 & $0.56(0.38,0.71)$ & 0.003 & $0.66(0.44,0.99)$ & 0.01 \\
\hline Tibialis Anterior & $0.61(0.17,0.92)$ & 0.02 & $0.82(0.76,0.99)$ & ns (0.15) & $0.46(0.13,1.00)$ & 0.02 \\
\hline Peroneus longus & $0.53(0.38,0.98)$ & 0.02 & $0.70(0.35,1.45)$ & ns (0.13) & $0.61(0.28,1.19)$ & 0.04 \\
\hline
\end{tabular}

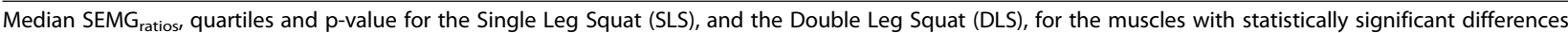
between sides in one or more of the time bins $1,6 / 7$ and 11 , for the 16 participants with ACL rupture.

SEMG $_{\text {ratio }}$ was calculated as the ratio of the average amplitude between injured and non-injured sides for each of the time bins $1,6 / 7$ and 11 , so that an equal activation in injured and non-injured sides would correspond to 1.0. The calculations were made for all six muscles recorded.

SLS and DLS are included in the Test for Substitution Patterns where altered movements (substitution patterns) were scored as observable, predefined deviations of postural orientation; for details see Subjects and methods section.

Time bin $=$ a time epoch. Time bin 1 corresponds to the instance prior to the beginning of the movement, time bin $6 / 7$ to the transition from flexion to extension and time bin 11 to the end of the movement.

$\mathrm{Q}_{1}, \mathrm{Q}_{3}=$ quartiles 1 and 3 .

$\mathrm{p}=\mathrm{p}$-value.

ns = non-significant.

quadriceps at transition from knee flexion to extension, the more pronounced the lateral displacement of the hippelvis region (Table 4). "Knee medial to supporting foot" was negatively correlated to $\mathrm{SEMG}_{\text {ratio }}$ of the gluteus medius in time bin $6 / 7, \mathrm{r}_{\mathrm{s}}=-0.73(\mathrm{p}=0.001,95 \%$ CI -0.90 to -0.36 ), indicating that the lower the muscle activity in gluteus medius at transition from knee flexion to extension, the more pronounced the displacement of the knee in relation to the supporting foot. "Displacement of trunk" was positively correlated to $\mathrm{SEMG}_{\text {ratio }}$ for gluteus medius in time bin $6 / 7, \mathrm{r}_{\mathrm{s}}=0.62(\mathrm{p}=0.01,95 \%$ CI 0.18 to $0.85)$ and negatively correlated to $\mathrm{SEMG}_{\text {ratio }}$ for tibialis anterior in time bin 11, $\mathrm{r}_{\mathrm{s}}=-0.50,(\mathrm{p}=0.047,95 \% \mathrm{CI}-0.80$ to -0.01 ). This indicates that high activity in gluteus

Table 4 Correlations between TSP points and SEMG ratios in Single- and Double Leg Squat (SLS, DLS)

\begin{tabular}{|c|c|c|c|}
\hline \multicolumn{4}{|l|}{ SLS } \\
\hline Substitution pattern according to TSP & $\mathrm{SEMG}_{\text {ratio }}$ for muscle & Time bin & $r_{s}(95 \% \mathrm{Cl}) \mathrm{p}$-value \\
\hline "lateral displacement of the hip-pelvis region on the supporting side" & biceps femoris & 1 & $-0.71(-0.89$ to -0.33$) 0.002$ \\
\hline "lateral displacement of the hip-pelvis region on the supporting side" & quadriceps & $6 / 7$ & $-0.54(-0.82$ to -0.06$) 0.03$ \\
\hline "knee medial to the supporting foot" & gluteus medius & $6 / 7$ & $-0.73(-0.90$ to -0.36$) 0.001$ \\
\hline "displacement of the trunk" & gluteus medius & $6 / 7$ & 0.62 (0.18 to 0.85$) 0.01$ \\
\hline "pronation of the foot" & tibialis anterior & 11 & $-0.60(-0.84$ to -0.14$) 0.015$ \\
\hline "displacement of the trunk" & tibialis anterior & 11 & $-0.50(-0.80$ to -0.01$) 0.047$ \\
\hline \multicolumn{4}{|l|}{ DLS } \\
\hline "displacement of body weight to either side" & tibialis anterior & 11 & $-0.51(-0.80$ to -0.02$) 0.043$ \\
\hline
\end{tabular}

Correlations between the points scored for the substitution patterns in injured side and $\mathrm{SEMG}_{\text {ratios }}$ for the muscles recorded, in the test-movements Single Leg

Squat (SLS) and Double Leg Squat (DLS), for the 16 participants with ACL rupture. Spearman's correlation coefficients, the $95 \%$ confidence interval and p-value are presented for time bins $1,6 / 7$ and 11 with statistically significant correlations.

$\mathrm{SEMG}_{\text {ratio }}$ was calculated as the ratio of the average amplitude between injured and non-injured sides for each of the time bins $1,6 / 7$ and 11 , so that an equal activation in injured and non-injured sides would correspond to 1.0. The calculations were made for all six muscles recorded.

SLS and DLS are included in the Test for Substitution Patterns where altered movements (substitution patterns) were scored as observable, predefined deviations of postural orientation; for details see Subjects and methods section.

Time bin $=$ a time epoch. Time bin 1 corresponds to the instance prior to the beginning of the movement, time bin $6 / 7$ to the transition from flexion to extension and time bin 11 to the end of the movement.

$r_{\mathrm{s}}=$ Spearman's correlation coefficient.

$95 \% \mathrm{Cl}=95 \%$ confidence interval. 
medius on the injured side at transition from knee flexion to extension and low activity in tibialis anterior on the injured side at the end of the SLS, were associated with more pronounced displacement of the trunk. Finally, there was a negative correlation between "pronation of foot" and SEMG ${ }_{\text {ratio }}$ for tibialis anterior in time bin 11, $\mathrm{r}_{\mathrm{s}}=-0.60,(\mathrm{p}=0.015,95 \% \mathrm{CI}-0.84$ to -0.14$)$, indicating that low activity in tibialis anterior at the end of the movement was associated to a more pronounced pronation of the foot.

For DLS, "displacement of body weight to either side" was negatively correlated to $\mathrm{SEMG}_{\text {ratio }}$ for tibialis anterior in time bin $11, \mathrm{r}_{\mathrm{s}}=-0.51(\mathrm{p}=0.043,95 \% \mathrm{CI}-0.80$ to -0.02 ), indicating that low activity in tibialis anterior at the end of the movement, was associated to a more pronounced displacement of body weight (Table 4).

\section{Discussion}

More pronounced substitution patterns were observed on participants' injured side, in agreement with previous studies of the TSP [3,9]. Deviating muscular activity, in general lower activity on the injured as compared to the non-injured side, and deviations between injured and non-injured side in antagonistic activity within the injured side were found during both SLS and DLS. Correlations between individual substitution patterns and deviations in the activity of specific muscles at specific times were seen, not only in muscles acting directly on the knee joint, but also on adjacent joints. These results support the notion that specific altered movement patterns may be associated with deviations in muscular activity.

The $\mathrm{SEMG}_{\text {ratio }}$ was calculated for six muscles at three time bins (time bin 1, 6/7 and 11) during SLS and DLS, amounting to 18 comparisons between injured and noninjured sides for each movement. Out of these 18 comparisons for SLS and DLS respectively, 3 for SLS and 9 for DLS showed statistically significantly differences (Table 3 ). With only one exception, all these differences constituted a lower activity on the injured as compared to the noninjured side prior to beginning of movement, at transition from flexion to extension as well as at the end of movement. In DLS, a significantly lower activity was seen in four of six muscles prior to the beginning of movement, two of six muscles in transition from flexion to extension and in three of six muscles at end of movement. Notably, quadriceps had a significantly lower activity on the injured side in all three phases of the movement. A lower activity in quadriceps muscle at transition from flexion to extension and at end also was found during SLS. A key to understanding mechanisms underlying altered movement patterns will be to determine if changes in muscular activation such as those described here occur as a direct consequence of ACL injury, or whether they are adaptive and act to compensate for loss of joint stability and/or sensory afferent input. While such analysis of causality was beyond the scope of the present study, a first step may be to put our results in perspective of previous findings.

One reason for the low injured/non-injured ratios at transition from knee flexion to extension in quadriceps in SLS and DLS can be the proposed arthrogenic muscle inhibition in quadriceps, describing the inability to contract the muscle after joint injury beyond conscious, voluntary control [36]. This is found to be common both in individuals with ACL-injury and ACL-reconstruction, often observed bilaterally [37]. Although muscle inhibition was not assessed in the individuals in the present study, it is likely that the occurrence of quadriceps inhibition could explain part of the low injured/non-injured ratios in quadriceps found in the individuals studied in this study.

Another reason for a decrease in muscle activity on the injured side could be muscle weakness, often reported after ACL injury, especially in quadriceps and hamstrings [38] in which a quadriceps strength deficit of $20 \%$ preoperatively and also 1 year after ACL reconstruction is reported [39]. EMG amplitude reflects to some degree muscle force development in the non-fatigued state [40]. When comparing EMG amplitudes between muscles or individuals, it is common to normalize the values against the EMG amplitude recorded at maximal voluntary contraction (MVC). We chose not to perform MVCs due to the relatively short time that had passed after the ACL injury, since MVCs could endanger instability in the injured knee joint, with the associated risk of subsequent pain or re-injury to the affected knee but also a risk of pain during the performance of MVCs that could affect the assessment itself. Therefore, no information on muscle force development in our participants was available. Thus, it cannot be excluded that muscle weakness can partly reflect the lower EMG activity on the injured side, especially when all loading is concentrated on one leg, as in the SLS. Whether such assumed muscle weakness was present before injury or occurred as a (direct or adaptive) consequence of injury is not known. However, since scores on the KOOS for this group of participants were similar to individuals with ACL-injury assigned for ligament reconstruction the tasks performed in the present study may be argued to be submaximal and well within participants' capacity. More importantly, the results of the deviating antagonistic activity patterns with a lower quadriceps/hamstrings ratio within injured as compared to within non-injured sides prior to the beginning of DLS movement, at end of both SLS and DLS, and for the tibialis/gastrocnemius ratio at end of DLS, assessed in phases of the movement in which muscle strength is not challenged, cannot be explained only in terms of muscle weakness, but further point towards an altered muscular activation pattern affecting sensorimotor control and therefore most likely contributing to 
the altered movement patterns. These discrepancies may be an important factor underlying the development of substitution patterns, and should be further investigated in future studies.

The only muscle with higher activity on the injured as compared to non-injured side was biceps femoris just prior to the beginning of DLS movement. The hamstrings and the ACL are postulated to act in synergy to prevent anterior tibial displacement during quadriceps contraction and it also has been suggested that increased hamstring activity and quadriceps inhibition may occur as a reactive muscle strategy to regain functional stability [41]. However, investigations of hamstrings muscle activity show varying results. During gait, Boerboom et al. reported high hamstrings activity in the beginning and at the end of a stride in both individuals with ACL injury and in controls [42], while Alkjaer et al. [43], found no differences in EMG patterns of hamstrings muscles when comparing individuals with ACL injury to controls. Swanik et al. found increased hamstrings activity during landing from a jump in individuals with ACL injury and concluded that this reactive muscle activity was presumably an attempt to regain functional stability [41]. The reported changes in biceps femoris muscle activity, as found prior to the beginning of DLS movement in the present study and in accordance with Swanik et al. [41], might indicate adaptive changes in motor control as a strategy to regain functional stability. If so, this could be speculated to be a result of changes in sensory feedback due to the injured ligament, and a modification in existing motor programs by regaining or relearning new movement patterns. Together with the results of the deviating antagonistic activity patterns of quadriceps/hamstrings- and tibialis/gastrocnemius ratio within the injured as compared to the non-injured sides in the present study, adaptive changes in sensorimotor control certainly cannot be excluded.

When performing DLS, it is possible to shift more loading to the non-injured side, which could explain the lower $\mathrm{SEMG}_{\text {ratio }}$ on the injured side. This also was indicated by the scoring of the TSP, since "displacement of body weight to either side" was only observed on the injured side. The mechanism underlying the displacement is unclear, but one plausible explanation may be the experience of pain at time of injury resulting in a subsequent fear of movement. Individuals with ACL injury may have lower muscle strength on the injured side even after one year of rehabilitation [38]. This decreased strength might be affected by habitual displacement of bodyweight or limited attention in rehabilitation programs to weight bearing. Therefore, it would be important to make the individual aware of habitual displacement of body weight and to address this in training of sensorimotor control, strength and endurance through augmented visual feedback using mirrors, or biofeedback.
We found correlations between low SEMG $\mathrm{Gatio}_{\text {for glu- }}$ teus medius and more pronounced substitution patterns of "knee medial to supporting foot" during SLS. This is in accordance with Mauntel et al., who found associations between medial knee displacement and decreased co-activation of gluteal to hip adductor muscles in noninjured individuals performing SLS [28]. In addition, we found correlations between low SEMG ${ }_{\text {ratio }}$ for quadriceps muscle and more pronounced "lateral displacement of hip-pelvis region". These findings, together with findings of substitution patterns in the whole lower extremity and trunk as measured with the TSP in previous studies $[3,9]$, and by analogy with the functional tests used by Whatman et al. rating trunk, pelvis, knee and foot [18], indicate that the whole kinetic chain should be observed in assessment of altered movement patterns.

Some limitations should be considered when the findings of this study are interpreted. The amplitude and frequency content of the SEMG signal, as well as the susceptibility to crosstalk from adjacent muscles, is primarily dependent on the distance between the electrodes and the active muscle fibers. Electromagnetic interference and movement artefacts may disturb the signal, and contraction velocity, muscle length, tissue thickness, temperature etc. also can influence the signal, why these factors have to be controlled and minimized when comparisons between individuals, muscles or sessions are performed [44]. Since all comparisons were conducted between injured and non-injured sides in the same individual on one occasion, the above mentioned variations were kept to a minimum. Since the movement speed can influence SEMG amplitude [45], a metronome was used to diminish differences between sides and since the same examiner mounted all electrodes, the variation in electrode application and placement was kept to a minimum.

In accordance with previous work we found noticeable variations in absolute amplitudes between individuals, Additional file 1 [46]. By calculating $\mathrm{SEMG}_{\text {ratio }}$ these differences were diminished. Yet, the low amplitudes, especially in time bin 1 and 11, in which a small change in amplitude can induce considerable change in ratio, might imply some uncertainty in the results. Therefore, $\mathrm{SEMG}_{\text {ratios }}$ calculated for higher amplitudes, as in bin 6/7 with transition from flexion to extension, had a stronger influence on our conclusions.

Another aspect not yet investigated is if altered movement patterns and muscular activity are dissimilar in different subgroups, for example if divided into subgroups of men and women. Diminished muscular protection of passive structures of the knee have been described in women as compared to men $[47,48]$, and Myer et al. have suggested that females utilize neuromuscular activation strategies which may contribute to "dynamic valgus" when performing high-risk manoeuvres [49]. However, 
since the present study was a first evaluation of muscle activity during altered movement patterns scored with TSP, a distribution into subgroups of men and women was neither achievable, nor within the scope of the study, but ought to be investigated in future studies.

\section{Conclusions}

More pronounced altered movement patterns were observed on participants' injured than on non-injured side. Deviations in SEMG activity of specific muscles between injured and non-injured sides were seen during both SLS and DLS - with generally lower activity on the injured side. Associations between these deviations and specific altered movement patterns were found, particularly during SLS. This was found not only for muscles acting directly across the knee joint, but also for the gluteus medius muscle. Also, deviating antagonistic muscular activity patterns in quadriceps/hamstrings and in tibialis/gastrocnemius within injured as compared to non-injured sides were found. These findings suggest that altered movement patterns during functional assessments and rehabilitative exercise such as the SLS and DLS - more strenuous than gait, but not as demanding as jumping - are not only caused by altered biomechanics and/or muscle weakness but probably also by altered sensorimotor control. We suggest that in the evaluation and rehabilitation of ACL injury, assessments of specific altered movement patterns, using for instance the TSP, might provide indications of specific alterations in sensorimotor control and therefore should be considered as a complement to other assessments.

\section{Additional file}

Additional file 1: Absolute amplitudes Trulsson et al. 2014. Absolute amplitudes. Median and quartiles $\left(Q_{1}\right.$ and $\left.Q_{3}\right)$ for absolute amplitudes for each time bin, each muscle, for non-injured and injured sides for the test-movements Single Leg Squat (SLS) and the Double Leg Squat (DLS) for 16 participants with $A C L$ rupture.

\section{Competing interests}

The authors declare that they have no competing interests.

\section{Authors' contributions}

AT, CG and MG provided the concept, idea and fund procurement, and AT, MM, G-AH, CG and MG provided research design. AT, MM and CG provided the data collection. AT and MG performed the data analysis and the statistical analysis in consultation with Professor Jonas Björk, division of occupational and environmental medicine at Lund University. AT was mainly responsible for the writing, while AT, CG and MG drafted the manuscript and all authors read and approved the final version. AT provided project management and the Department of Health Sciences, Division of Physiotherapy, Lund University provided the equipment.

\section{Acknowledgements}

We would kindly like to acknowledge Professor Jonas Björk, division of occupational and environmental medicine at Lund University, for statistical consultation, RPT Örjan Sundewall, Department of Orthopedics at Skane University Hospital for participant management, and Department of Health Sciences, Division of Physiotherapy, Lund University, Sweden for providing the equipment.

\section{Funding}

This study was funded by the Swedish Research Council, Project nos. 14015 (PI Martin Garwicz), Swedish National Centre for Research in Sports, Medical Faculty of Lund University, Sweden, Region Skane, Sweden, Ann-Mari och Ragnar Hemborgs Minnesfond, Lund University, Sweden, Emy Thulins Forskningsfond, Lund University, Sweden and Professor Stig Radners fond, Lund University, Sweden.

\section{Author details}

'Department of Health Sciences, Physiotherapy, Lund University, Lund, Sweden. 'Department of Rehabilitation Medicine, Skane University Hospital, Lund, Sweden. ${ }^{3}$ Occupational and Environmental Medicine, Lund University, and University and Regional Laboratories Region Scania, Lund, Sweden. ${ }^{4}$ Centre for Teaching and Learning, Lund University, Lund, Sweden. ${ }^{5}$ Department of Experimental Medical Science, Neuronano Research Center, Lund University, Lund, Sweden.

Received: 18 December 2014 Accepted: 16 January 2015

Published online: 13 February 2015

\section{References}

1. Rudolph KS, Snyder-Mackler L. Effect of dynamic stability on a step task in ACL deficient individuals. J Electromyogr Kinesiol. 2004;14(5):565-75.

2. Ingersoll CD, Grindstaff TL, Pietrosimone BG, Hart JM. Neuromuscular consequences of anterior cruciate ligament injury. Clin Sports Med. 2008:27(3):383-404. vii.

3. Trulsson A, Garwicz M, Ageberg E. Postural orientation in subjects with anterior cruciate ligament injury: development and first evaluation of a new observational test battery. Knee Surg Sports Traumatol Arthrosc 2010;18(6):814-23.

4. Roos EM, Roos HP, Lohmander LS, Ekdahl C, Beynnon BD. Knee Injury and Osteoarthritis Outcome Score (KOOS)-development of a self-administered outcome measure. J Orthop Sports Phys Ther. 1998;28(2):88-96.

5. Neeter C, Gustavsson A, Thomee P, Augustsson J, Thomee R, Karlsson J. Development of a strength test battery for evaluating leg muscle power after anterior cruciate ligament injury and reconstruction. Knee Surg Sports Traumatol Arthrosc. 2006;14(6):571-80.

6. Padua DA, Marshall SW, Boling MC, Thigpen CA, Garrett Jr WE, Beutler Al. The Landing Error Scoring System (LESS) Is a valid and reliable clinical assessment tool of jump-landing biomechanics: the JUMP-ACL study. Am J Sports Med. 2009:37(10):1996-2002.

7. Augustsson J, Thomee R. Ability of closed and open kinetic chain tests of muscular strength to assess functional performance. Scand J Med Sci Sports. 2000;10(3):164-8.

8. Gustavsson A, Neeter C, Thomee P, Gravare Silbernagel K, Augustsson J, Thomee $\mathrm{R}$, et al. A test battery for evaluating hop performance in patients with an $\mathrm{ACL}$ injury and patients who have undergone $\mathrm{ACL}$ reconstruction. Knee Surg Sports Traumatol Arthrosc. 2006;14(8):778-88.

9. Trulsson A, Roos EM, Ageberg E, Garwicz M. Relationships between postural orientation and self reported function, hop performance and muscle power in subjects with anterior cruciate ligament injury. BMC Musculoskelet Disord. 2010;11:143.

10. Frost D, Andersen J, Lam T, Finlay T, Darby K, McGill S. The relationship between general measures of fitness, passive range of motion and whole-body movement quality. Ergonomics. 2013;56(4):637-49.

11. Lephart S, Fu F. Proprioception and neuromuscular control in joint stability In: Lephart S, Fu F, editors. Proprioception and neuromuscular control in joint stability, Human kinetics. 2000. p. 5-29. 77-88, 171-196.

12. Williams GN, Chmielewski T, Rudolph K, Buchanan TS, Snyder-Mackler L. Dynamic knee stability: current theory and implications for clinicians and scientists. J Orthop Sports Phys Ther. 2001:31(10):546-66.

13. Solomonow M. Sensory-motor control of ligaments and associated neuromuscular disorders. J Electromyogr Kinesiol. 2006;16(6):549-67.

14. Beynnon BD, Johnson RJ, Abate JA, Fleming BC, Nichols CE. Treatment of anterior cruciate ligament injuries, part I. Am J Sports Med. 2005:33(10):1579-602.

15. Bryant AL, Newton RU, Steele J. Successful feed-forward strategies following ACL injury and reconstruction. J Electromyogr Kinesiol. 2009;19(5):988-97.

16. Ageberg E, Bennell KL, Hunt MA, Simic M, Roos EM, Creaby MW. Validity and inter-rater reliability of medio-lateral knee motion observed during a single-limb mini squat. BMC Musculoskelet Disord. 2010;11:265. 
17. Crossley KM, Zhang WJ, Schache AG, Bryant A, Cowan SM. Performance on the single-leg squat task indicates hip abductor muscle function. Am J Sports Med. 2011;39(4):866-73.

18. Whatman C, Hing W, Hume P. Physiotherapist agreement when visually rating movement quality during lower extremity functional screening tests. Phys Ther Sport. 2012;13(2):87-96.

19. Whatman $C$, Hume $P$, Hing W. The reliability and validity of physiotherapist visual rating of dynamic pelvis and knee alignment in young athletes. Phys Ther Sport. 2012;14(3):168-74

20. Hewett TE, Myer GD, Ford KR, Heidt Jr RS, Colosimo AJ, McLean SG, et al. Biomechanical measures of neuromuscular control and valgus loading of the knee predict anterior cruciate ligament injury risk in female athletes: a prospective study. Am J Sports Med. 2005;33(4):492-501.

21. Escamilla RF, Macleod TD, Wilk KE, Paulos L, Andrews JR. Cruciate ligament loading during common knee rehabilitation exercises. Proc Inst Mech Eng H. 2012;226(9):670-80.

22. Chmielewski TL, Hodges MJ, Horodyski M, Bishop MD, Conrad BP, Tillman SM. Investigation of clinician agreement in evaluating movement quality during unilateral lower extremity functional tasks: a comparison of 2 rating methods. J Orthop Sports Phys Ther. 2007;37(3):122-9.

23. Shumway-Cook A, Woollacott MH. Normal postural control. In: Motor control translating research into clinical practice. 4th ed. Baltimore, Philadelphia: Lippincott Williams \& Wilkins; 2011. p. 161-94.

24. Tanamas S, Hanna FS, Cicuttini FM, Wluka AE, Berry P, Urquhart DM. Does knee malalignment increase the risk of development and progression of knee osteoarthritis? a systematic review. Arthritis Rheum. 2009;61(4):459-67.

25. Papadonikolakis A, Cooper L, Stergiou N, Georgoulis AD, Soucacos PN. Compensatory mechanisms in anterior cruciate ligament deficiency. Knee Surg Sports Traumatol Arthrosc. 2003;11(4):235-43.

26. Wikstrom EA, Tillman MD, Chmielewski TL, Borsa PA. Measurement and evaluation of dynamic joint stability of the knee and ankle after injury. Sports Med. 2006;36(5):393-410.

27. Padua DA, Bell DR, Clark MA. Neuromuscular characteristics of individuals displaying excessive medial knee displacement. J Athl Train. 2012;47(5):525-36.

28. Mauntel TC, Begalle RL, Cram TR, Frank BS, Hirth CJ, Blackburn T, et al. The effects of lower extremity muscle activation and passive range of motion on single leg squat performance. J Strength Cond Res. 2013;27(7):1813-23.

29. Irrgang JJ, Anderson AF, Boland AL, Harner CD, Kurosaka M, Neyret $P$, et al. Development and validation of the international knee documentation committee subjective knee form. Am J Sports Med. 2001;29(5):600-13.

30. Tegner $Y$, Lysholm J. Rating systems in the evaluation of knee ligament injuries. Clin Orthop Relat Res. 1985;198:43-9.

31. Surface Electromyography for the Non-Invasive Assessment of Muscles, http://seniam.org/sensor_location.htm. Accessed 20150115

32. Arendt-Nielsen L, Graven-Nielsen T, Svarrer H, Svensson P. The influence of low back pain on muscle activity and coordination during gait: a clinical and experimental study. Pain. 1996;64(2):231-40.

33. Lariviere $C$, Arsenault $A B$. On the use of EMG-ratios to assess the coordination of back muscles. Clin Biomech (Bristol, Avon). 2008;23(10):1209-19.

34. Hollander M, Wolfe D. Non-parametric statistical methods. 2nd ed. New York: John Wiley \& Sons Inc.; 1999.

35. Burnett DR, Campbell-Kyureghyan NH, Cerrito PB, Quesada PM. Symmetry of ground reaction forces and muscle activity in asymptomatic subjects during walking, sit-to-stand, and stand-to-sit tasks. J Electromyogr Kinesiol. 2011;21(4):610-5.

36. Hopkins JT, Ingersoll CD. Arthrogenic muscle inhibition: a limiting factor in joint rehabilitation. J Sport Rehabil. 2000;9(2):135-59.

37. Hart JM, Pietrosimone B, Hertel J, Ingersoll CD. Quadriceps activation following knee injuries: a systematic review. J Athl Train. 2010;45(1):87-97.

38. Thomas AC, Villwock M, Wojtys EM, Palmieri-Smith RM. Lower extremity muscle strength after anterior cruciate ligament injury and reconstruction. J Athl Train. 2013;48(5):610-20.

39. de Jong SN, van Caspel DR, van Haeff MJ, Saris DB. Functional assessment and muscle strength before and after reconstruction of chronic anterior cruciate ligament lesions. Arthroscopy. 2007;23(1):21-8. 28 e21-23.

40. Staudenmann D, Roeleveld K, Stegeman DF, van Dieen JH. Methodological aspects of SEMG recordings for force estimation-a tutorial and review. J Electromyogr Kinesiol. 2010;20(3):375-87.

41. Swanik CB, Lephart SM, Giraldo JL, Demont RG, Fu FH. Reactive muscle firing of anterior cruciate ligament-injured females during functional activities. J Athl Train. 1999;34(2):121-9.
42. Boerboom AL, Hof AL, Halbertsma JP, van Raaij JJ, Schenk W, Diercks RL, et al. Atypical hamstrings electromyographic activity as a compensatory mechanism in anterior cruciate ligament deficiency. Knee Surg Sports Traumatol Arthrosc. 2001:9(4):211-6.

43. Alkjaer T, Simonsen EB, Jorgensen U, Dyhre-Poulsen P. Evaluation of the walking pattern in two types of patients with anterior cruciate ligament deficiency: copers and non-copers. Eur J Appl Physiol. 2003;89(3-4):301-8.

44. Jensen $\mathrm{C}$, Vasseljen $\mathrm{O}$, Westgaard $\mathrm{RH}$. The influence of electrode position on bipolar surface electromyogram recordings of the upper trapezius muscle. Eur J Appl Physiol Occup Physiol. 1993;67(3):266-73.

45. Yang JF, Winter DA. Surface EMG profiles during different walking cadences in humans. Electroencephalogr Clin Neurophysiol. 1985;60(6):485-91.

46. Pierotti SE, Brand RA, Gabel RH, Pedersen DR, Clarke WR. Are leg electromyogram profiles symmetrical? J Orthop Res. 1991;9(5):720-9.

47. Ireland ML. The female ACL: why is it more prone to injury? Orthop Clin North Am. 2002;33(4):637-51.

48. Wojtys EM, Ashton-Miller JA, Huston LJ. A gender-related difference in the contribution of the knee musculature to sagittal-plane shear stiffness in subjects with similar knee laxity. J Bone Joint Surg. 2002;84-A(1):10-6.

49. Myer GD, Ford KR, Hewett TE. The effects of gender on quadriceps muscle activation strategies during a maneuver that mimics a high $\mathrm{ACL}$ injury risk position. J Electromyogr Kinesiol. 2005;15(2):181-9.

\section{Submit your next manuscript to BioMed Central and take full advantage of:}

- Convenient online submission

- Thorough peer review

- No space constraints or color figure charges

- Immediate publication on acceptance

- Inclusion in PubMed, CAS, Scopus and Google Scholar

- Research which is freely available for redistribution 